\title{
Brain Hemisphericity and Saudi Students' EFL Reading Comprehension
}

\author{
Manar Almanea \\ College of Languages and Translation \\ Imam Mohammad Ibn Saud Islamic University \\ Riyadh, Saudi Arabia \\ Email: malmanea@imamu.edu.sa
}

Received: 3/4/2021

Accepted: 6/19/2021

Published:6/24/2021

\begin{abstract}
The present study is concerned with the relationship between brain hemisphericity and the reading comprehension of adult Saudi EFL learners. The tendency to rely on one side of the brain over the other can affect the degree of success in learning a foreign language as well as the appropriateness of learning and teaching strategies. A total of 122 Saudi university-level participated in the study. The first part of the study examines whether or not there are significant differences between the performance of right-brained learners, left-brained learners, wholebrained learners, whole-brained learners favoring right mode, and whole-brained learners favoring left mode in an EFL reading comprehension test. The EFL reading comprehension includes main idea questions, inferential questions, literal-meaning questions and text-bound questions. The Hemispheric Mode Indicator ${ }^{\circledR}$ is used to determine hemispheric preference of the participants. Findings revealed significant superiority of the performance of left-brained learners as compared to right-brained learners and whole-brained learners favoring right mode. This result suggests that even in a foreign language learned after childhood, the left-hemisphere seems to control brain activities dealing with language. In the second part of the study, participants were trained to use a visual tool (Mind Mapping ${ }^{\circledR}$ ) to summarize the information of the reading passage before answering a parallel reading comprehension test. Whole-brained learners favoring right mode, and right-brained learners were the two groups who benefited the most from the visual tool. This result was expected since the visual tool activates some right hemispheric functions. It is concluded that learners with different modes of hemisphericity learn in different ways.
\end{abstract}

Keywords: English as a foreign language, hemisphericity, hemispheric dominance, individual differences, reading comprehension

Cite as: Almanea, M. (2021). Brain Hemisphericity and Saudi Students’ EFL Reading

Comprehension. Arab World English Journal, 12 (2) 436-456.

DOI: https://dx.doi.org/10.24093/awej/vol12no2.30 


\section{Introduction}

The concept of hemisphericity, sometimes called laterality, hemispheric dominance or hemisity, refers to the general tendency of individuals to rely on one of the brain hemispheres and its functioning mode more than the other (Bogen, 1975; McCarthy, 1978). Accordingly, it is possible to classify individuals as right-brained oriented, left-brained oriented, or whole-brained oriented persons. Even whole-brained individuals, though adept at using skills of both hemispheres adequately, usually show a slight preference for using one of the hemispheres over the other. They can be classified into whole-brained favoring right mode, whole-brained, and whole-brained favoring left mode (McCarthy\& Germain, 1993). Hemisphericity is argued to be the general determiner of many personality traits, thinking modes, learning styles, personality types, social behavior, etc. Recently, neurologists (Morton \& Rafto, 2006; 2010) revealed interesting findings that there are actual, biological brain-structure differences between left and right brain-oriented people. With that discovery, hemisphericity has become a topic worth revisiting.

Main intellectual functions "lateralized" to the right hemisphere are rhythm, music, spatial awareness, depth, synthesis, color, dimension, imagination, recognition of faces in addition to emotions and social abilities. It processes mostly concrete data. The right hemisphere is pragmatically proficient. It creates larger systems of holistic relationships and is adept at organizing data in terms of complex wholes (Riley, 1981). By contrast, the left hemisphere is dominant in mental skills encompassing activities like language, speech output, words, reasoning, logic, abstract data, numbers, sequence, linearity, analysis and lists. It seeks out details and specificity, and is linguistically proficient (Buzan \& Buzan, 2003; Chuang, 2006).

The accumulation of research about the brain hemispheres and language has strongly suggested that language is lateralized to the left hemisphere (Fromkin, Rodman \& Hyams, 2007). Accordingly, left-brained persons are predicted to be more skilled language users. It has been argued that most troubled, less successful readers, actually comprising over $90 \%$ of all unsuccessful readers, are right-brained (Croker, Bobell \& Wilon, 1995).Things are more complicated if the brain contains more than one independent language system.

\section{Research objectives}

The objective of the present study is two-fold. First, it investigates the possible role played by the hemisphericity mode on the level of EFL reading comprehension of universitylevel Saudi EFL learners. Specifically, it seeks to find out whether there are significant differences in the performance of left-brained learners (LBLs), right-brained learners (RBLs), whole-brained learners (WBLs), whole-brained favoring left mode (WBLM) and whole-brained favoring right mode (WBRM) in an EFL reading comprehension test. EFL reading comprehension levels addressed in the test are the literal and inferential levels. Second, the study assesses the effect of using a visual tool (which hypothetically suits RBLs) on the reading comprehension of learners of different hemispheric modes. The overall reading comprehension level will be considered as will as the specific levels of eliciting the main idea of the text, making inferences, deciding on the literal meaning of words, as well as accurately restating text details. 


\section{Research questions}

1. Are there statistically significant differences in EFL reading comprehension levels of RBLs, LBLs, WBLs, WBRM learners and WBLM learners?

2. Does the use of a visual tool (a right-brain function) significantly improve the levels of EFL readings of learners with different hemisphericity modes?

\section{Literature Review}

With the use of several sophisticated brain imaging techniques and MRI to trace brain activity and assess hemisphericity, the research of the neurologists Morton and Rafto, (2006; 2010) indicated that there are actual brain structure differences between left- and right-brain oriented people. This fact led them to postulate the existence of some sort of Executive System in the brain that is inherently and genetically embedded within either the left or the right hemisphere. They found some neuroanatomical differences in the suggested site of the brain's executive, the anterior cingulate cortex (ACC). With 98\% degree of accuracy, the ACC has been found to be $50 \%$ thicker on the same brain side as the subject's predetermined hemisphericity. According to the researchers, hemisphericity is responsible for the bias in thinking orientation, behavioral style and personality traits. Left-brained people are more skilled in areas that require left brain participation, like breaking the whole into parts, sequencing, verbalizing and analyzing. On the other hand, right-brained persons see the whole picture, visualize, synthesize, and are sensitive to emotions, beauty and rhythm. Whole-brained are equally adept in right and left brain processes. However, even among whole-brained groups, individuals may differ in exhibiting a slight preference for processing of one side of the brain over the other (Carthy, 1993).

\section{Hemisphericity and language}

Generally, left-brained individuals are more skilled in linguistic tasks than right-brained, since language is localized in the left hemisphere. In addition, language is linear, it consists of parts that constitute larger chunks, and it follows regular strict grammatical rules; all of these features suit left-hemisphere processing. Researchers have learned a lot about language and hemispheres by observing the effect of brain damage on language. It has been found that physical damage to the left hemisphere resulted in a dramatic speech loss, or in other words in different types of aphasia (Fromkin, et al., 2007). Phonological, syntactic and semantic linguistic abilities can be severely impaired. When the damage occurs in the right hemisphere, it results in deficiencies in facial recognition, pattern recognition, and some other cognitive abilities. Nevertheless, some researchers found that with injuries in the right hemisphere, some linguistic skills were still affected. The right hemisphere appears to be responsible for constructing a coherent discourse representation, integrating ideas across sentences, identifying main ideas and themes, making inferences, interpreting non-literal data like metaphors and humor and other pragmatic elements (Prat, 2004).

\section{Hemisphericity and foreign language}

There is strong scientific evidence that cerebral specialization of bilinguals differs from that of monolinguals (Fromkin et. al., 2007). Findings of previous studies indicated that language in the brain of a bilingual is less localized in the left hemisphere, but rather is available all through both hemispheres. More right brain involvement is found in bilinguals than in monolinguals. This is proved by speculating aphasic bilingual patients who had a trauma in the right 
hemisphere. They showed more language impairment than monolinguals suffering from the same damage in the right hemisphere. In addition, those patients suffer from language problems both in the first and second language, which indicated that both languages are distributed all around the two hemispheres.

Learner's age at the time of acquisition may affect hemispheric specialization of bilinguals. General conclusions show that early bilinguals who acquired the second language before the age of five process language in the left hemisphere, while adult bilinguals who learn the language after puberty show more right brain processing (Williams, 1999). The acquisition stage similarly affects bilingual hemispheric lateralization. During the initial stages of language acquisition, the focus of learners is more on content words than function words and on meaning than form. Accordingly, it can be hypothesized that during these initial stages, the right hemisphere contributes more than the left hemisphere. However, as the learner advances, left brain processes become dominant. The manner of acquisition may be an additional variable that affects hemisphericity. Formal language learning emphasizes the metalinguistic features of that language and draws attention to the structure of the language, while informal acquisition setting is natural and communicative. Thus, in a formal setting, more left brain processes are activated, while in the informal setting there are signs of right brain involvement (Fromkin et al., 2007; Seliger, 1982).

Few empirical studies have been conducted on the effect of hemisphericity on second language/ foreign language performance. Douglas (1982) examined EFL proficiency and hemisphericity. He found that learners who perceived themselves to be good language learners performed better in left hemispheric abilities than right hemispheric ones. Against expectation, right hemisphericity seems to positively correlate with performance in grammatical competence, listening comprehension, and overall test score. Participants were Arab and Spanish students learning English in the U.S. The participation of the right hemisphere was noticed in the Arab sample but not the Spanish. The researcher concluded that the differences between the orthographic systems of Arabic and English impacted hemispheric participation. If the two orthographies of the two languages are different, more participation is required from the visual right hemisphere. Overall findings indicate that the right hemisphere is involved in the processing of linguistic data in bilinguals more than it is in monolinguals, particularly for those who learned the second language sometime later than their first language, and for those who learn the second language in an informal setting.

Robertson (2000) investigated the subject of foreign language reading and hemispheric specialization and asserted that more right-brain involvement is manifested during early stages of learning a language. That is especially true for young foreign language learners. Greater participation of the right hemisphere is evidenced when the orthography of the foreign language differs from that of the first language.

From a different point of view, Qi et al. (2014) concluded that there is evidence of the right hemispheric interaction with foreign language learning (specifically Mandarin Chinese). The study examined the relationship between the white matter microstructures in both hemispheres (as measured by diffusion tensor imaging and success in a four-week Mandarin Chinese course among adult English learners. Greater success is noticed among participants who have more 
right hemispheric participation rather than left hemispheric interaction. It can be argued, though, that the special Chinese alphabet characters might require more right brain functions. Foreign languages that use phonological writing systems may have different findings.

In a recent study, Qi et al. (2019) similarly discussed the important role of the right hemisphere in the process of foreign language learning. Greater pre-training activation in the right inferior frontal gyrus (IFG) part of the brain to Mandarin speech among English- speaking learners was associated with better Mandarin attainment at the end of the course. After four weeks of learning, learners showed overall increased activation in left IFG and left Superior Parietal Lobule (SPL) to Mandarin speech. Immediate attainment was associated with greater pre-to-post reduction of right IFG activation to Mandarin speech but also greater enhancement of resting-state connectivity between this region and both left IFG and left SPL. These findings suggest that successful holistic foreign language acquisition in human adulthood requires right IFG engagement during initial learning but right IFG disengagement for long-term retention of language skills.

Qi and Legault (2020) found that prior to learning, the neural characteristics of the left hemisphere predict the success particularly of future speech sound learning. Yet higher-level learning was found to be predicted by a more distributed network, including the right hemisphere and bilateral brain structures. The researchers argued that a dynamic bilateral framework involving neural correlates both within and between the two hemispheres underlies the ultimate success of language learning.

The above discussion of previous studies regarding the relationship between hemisphericity and foreign language learning suggests some right hemisphere interaction in the process of learning a foreign language, at least at the initial stages of that process. Bilinguals seem to exhibit more right hemisphere linguistic participation than monolinguals Yet, the roles of the hemispheres in learning a language are affected by many factors, such as learner's age, learning situation, stage of acquisition, and orthography of the foreign language. The present study attempts to examine these conclusions and to investigate the relationship between hemisphericity and foreign language reading comprehension in a different environment and with speakers of a different first language.

\section{Method}

The present study is an experimental one following a quantitative research design. It is divided into two parts. The first part investigates whether or not there are significant differences among EFL learners with different hemisphericity modes in their performance in an EFL reading comprehension test. The second part tests the effect of using a visual learning tool (a mind map) on learners' performance with different hemsiphericity modes in a parallel EFL reading comprehension test, with all other variables sought to be controlled.

\section{Participants}

The experimental group of participants consisted of Saudi 61 Arab university-level EFL learners. A control group was needed especially for the second part of the study in order to determine if the change in the performance, if any, is not attributed to some other factor. The control group also consisted of 61 Saudi Arab EFL learners. The assignment of subjects to either 
group was carried out randomly and automatically by a computer program that assigned students to different classes. The students are not assigned to these classes on the basis of any criteria. Moreover, to determine which group will be the experimental group, and which one the control group, a flip of the coin was used to minimize subjective decisions. Participants were all enrolled in Level Two (first year) at the Faculty of English in Imam Mohammad Ibn Saud Islamic University in Riyadh. All of the participants were at their initial stages of learning English as a foreign language; none of them acquired it in their childhood. They were all exposed to English in a formal way inside the classroom. Their ages range from 19 to 22 years. They have completed two independent EFL Reading and Comprehension courses at the university level, and they were registered at their third course at the time of the implementation of the study. Their consent to participate in the study was obtained prior to the implementation of the study.

\section{Instruments}

In order to determine the participants' hemisphericity mode, the Hemispheric Mode Indicator ${ }^{\circledR}$ (HMI) has been used. It is a standardized questionnaire developed by McCarthy (1987) and has been used by researchers to determine hemisphericity when brain-imaging and other advanced technological methods are not feasible. Its content and concurrent validity and reliability has been calculated and proven by Lieberman (1986). It is a bi-polar questionnaire consisting of 32 items that are rated on a Likert-type scale. The scoring of the HMI, as explained by McCarthy (1987), classifies participants into five groups; left-brained, right-brained, wholebrained, whole-brained preferring left-mode, and whole-brained preferring right mode. In order to avoid any possible misunderstanding of the questionnaire, it was translated into Arabic. The translation has been validated through back translation by two Arabic-English translation professionals.

EFL reading comprehension has been assessed by the use of two parallel reading comprehension tests adapted from $\mathrm{Ou}$ (2006). The two tests (the pretest and the posttest) are based on the principles and guidelines of the TOEFL test. They are specifically designed for EFL learners. All the questions are multiple-choice questions. Both tests consist of five passages (250 to 350 words long) from a variety of academic expository texts with a total of 50 questions each. Questions are classified into four groups. There are main-idea questions that test the reader's understanding of the main idea of the passage, inferential questions that test the participants' ability to understand what the writer implied but did not state, literal meaning questions that required the participants to identify the meaning of a particular word, and textbound questions which require a restatement of what the writer stated in the passage. The validity and reliability of the tests were established by showing the tests to four professionals and specialists in EFL reading comprehension. A pilot study was also conducted prior to the actual study to reveal any problems or difficulties in the study's instruments.

\section{Procedures}

\section{First part of the study}

Participants were grouped into different hemisphericity groups. They took the first version of the EFL reading comprehension test. The mean scores of the different hemisphericity groups were compared to trace any statistical significant difference between them. To examine whether the differences between the performances of different hemisphericity groups are statistically significant, one-way ANOVA is applied to the results. 


\section{Second part of the study}

During the second part of the study, participants in the experimental group were trained to use the visual tool Mind Mapping ( ${ }^{\circledR}$ to summarize texts. Mind Mapping was chosen because it suits right brain functions, since it presents information visually in a spatial way, gives a holistic view of the topic, incorporates colors, symbols, associations, and keywords. A program developed by a professional training center was administered to the participants to train them on the use of Mind Mapping. For mastery of the tool, the program was divided into three phases. The first phase lasted for two weeks and its objective was to give the participants the basic, general background knowledge about Mind Mapping ${ }^{\circledR}$ and to prepare them for the training course. As a kind of introduction, they were assigned certain parts of Buzan's and Buzan's (2003) The Mind Map Book to read. Those parts included a brief description of the Mind Map, its uses, and how to apply it, along with some visual examples of mind maps. To ensure that participants had read the material, a quiz was administered at the beginning of the second phase.

In the second phase, participants attended a three-day training session. The course was given by a certified trainer in Mind Mapping with a total of 12 training hours. The medium of instruction was Arabic, to ensure participants' understanding of the topic, and to reduce any effect of linguistic ambiguity.

The third phase started after the end of the training course. The instructor of the participants asked the students to compose mind maps after every reading passage they took. Mind maps were collected and handed to the researcher after every class. Figure one shows a sample of the students' mind maps which summarized information from a reading passage.

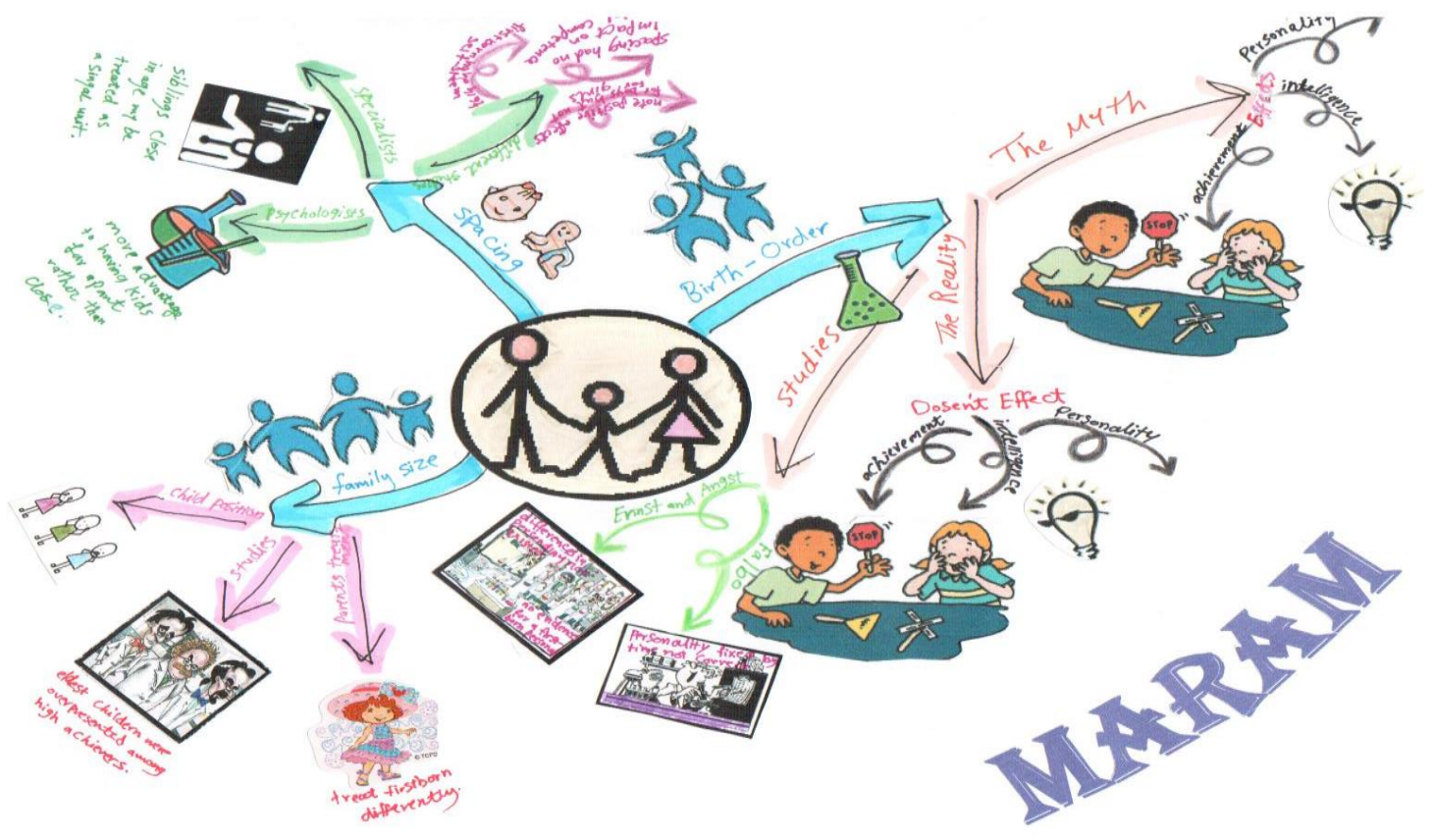

Figure1. A mind map composed by one participant to summarize ideas of a reading comprehension tex 
The posttest was conducted three weeks after the administration of the pretest. Both the experimental and the control group took the posttest. The participants in the experimental group were directed to compose a mind map after reading the passage and before answering any question. They were given some extra time as they required. Their mean scores in the pretest and the posttest were compared to determine any significant difference. A matched, two-tailed $t$-test is used for that purpose. To eliminate the possible interference of other unobserved variables which can affect the results, the mean scores of the control group in the pretest and posttest are taken into consideration. If the two groups' performances in the pretests are almost equivalent, any difference in their performance in posttests can be attributed to the variable examined in the study (the use of a visual tool). with all other variables controlled. The pretest and posttest mean scores of the two groups were compared, using the independent $t$-test formula which is used to compare mean scores of two groups.

\section{Results of the first part of the study}

The first part of the study answers the following question:

1. Are there statistically significant differences in EFL reading comprehension levels of RBLs, LBLs, WBLs, WBRM learners and WBLM learners?

The following sections provide answers to it.

\section{The results of the $\mathrm{HMI}$}

The analysis of the results of the HMI indicates that there are 16 left-brained participants, 17 right-brained participants, and a total of 28 whole-brained participants (comprising $45.9 \%$ of all participants), including those preferring either mode (Table one).

Table 1 Distribution of the participants according to their hemisphericity as measured by the HMI

\begin{tabular}{|c|c|c|c|c|c|c|}
\hline Hemisphericity & & & Frequency & Percent & Valid Percent & $\begin{array}{l}\text { Cumulative } \\
\text { Percent }\end{array}$ \\
\hline Left-brained & & & 16 & 13.1 & 26.2 & 26.2 \\
\hline $\begin{array}{l}\text { Whole-brained } \\
\text { mode }\end{array}$ & favoring & left & 10 & 8.2 & 16.4 & 42.6 \\
\hline Whole-brained & & & 5 & 4.1 & 8.2 & 50.8 \\
\hline $\begin{array}{l}\text { Whole-brained } \\
\text { mode }\end{array}$ & favoring & right & 13 & 10.7 & 21.3 & 72.1 \\
\hline Right-brained & & & 17 & 13.9 & 27.9 & 100.0 \\
\hline Total & & & 61 & 50.0 & 100.0 & \\
\hline
\end{tabular}

This result is similar to that of Saleh (2001), who found the whole-brained group to be the largest group in her sample. The high number of whole-brained participants can thus be the result of the way the whole-brain group is defined. Saleh (2001) considered the whole-brain group to include whole-brained participants, whole-brained favoring left mode and whole-brained favoring right mode. It seems that it may be more reasonable to treat each group as independent, keeping in mind that the questionnaire depends on conscious, personal reflections that are more absolute than accurate. Accordingly, the results of this study are based on the recognition of each 
group as independent. There are 10 participants who are whole-brained favoring left mode, 13 participants who are whole-brained favoring right mode, and five whole-brained participants.

\section{The results of the reading comprehension test}

The total mean scores of different hemisphericity groups in the reading comprehension test are presented in Table two.

Table 2 Total mean scores of the hemisphericity groups

\begin{tabular}{ll|l|l|l}
\hline & & $N$ & Mean & Std. Deviation \\
\hline Total score & Left-brained & 16 & .57 & .116 \\
& $\begin{array}{l}\text { Whole-brained } \\
\text { favoring left mode }\end{array}$ & 10 & .45 & .148 \\
Whole-brained & 5 & .50 & .075 \\
& $\begin{array}{l}\text { Whole-brained } \\
\text { favoring right mode }\end{array}$ & 13 & .41 & .092 \\
& Right-brained & 17 & .44 & .105 \\
Total & 61 & .48 & .124 \\
\hline
\end{tabular}

As was expected, the highest total mean score was obtained by left-brained participants 0.57.This result is similar to many others like Riley's (1981), who found that the highest performance is achieved by left-brained participants. Those are followed by the mean score of the WBLs 0.50 . The lowest mean score was that of WBRM 0.41 .

In order to test whether the differences in the performance of hemisphericity groups are statistically significant, one-way ANOVA and Tukey HSD formulae were applied to the results. The difference between the performance of left-brained participants on the one hand, and both right-brained participants as well as whole-brained participants favoring right mode, has proved to be statistically significant at the 0.05 alpha level, in favor of left-brained. So, the answer to question one is yes.

Since the literature indicated that the type of questions in the test usually affects the performance of different hemisphericity groups, it is essential at this point to examine the performance of hemisphericity groups in answers to different types of questions. The reading comprehension pretest includes five main-idea questions, 11 inferential questions, 14 literal meaning questions, and 20 text-bound questions. These four types of questions measure the reading comprehension skills of identifying main thought, drawing inferences about the content, understanding word meanings in context, and answering specific text-based questions.

\section{Performance in main idea questions}

There are five main idea questions, one for each "untitled" reading passage. The reader has to choose the correct main idea, among some distractor choices that represent either irrelevant ideas or some unimportant ones. Previous research indicated that deciding on the main theme of the passage requires right hemisphere participation. Accordingly, it was expected that rightbrained participants would perform better in this type of questions. The results show that all participants, including right-brained, performed the highest in answers to main idea questions, as compared to their performance to other types of questions. The highest mean score was achieved 
by left-brained participants while the lowest was that of whole-brained favoring right mode, and right-brained (Table three). Yet, statistical differences between different groups' mean scores were insignificant.

Table 3. Mean scores of answers to main idea questions

\begin{tabular}{|c|c|c|c|c|}
\hline & & $\mathrm{N}$ & Mean & Std. Deviation \\
\hline \multirow[t]{6}{*}{ Main idea } & Left-brained & 16 & .81 & .171 \\
\hline & $\begin{array}{l}\text { Whole-brained } \\
\text { favoring left mode }\end{array}$ & 10 & .76 & .126 \\
\hline & Whole-brained & 5 & .76 & .261 \\
\hline & $\begin{array}{l}\text { Whole-brained } \\
\text { favoring right mode }\end{array}$ & 13 & .74 & .206 \\
\hline & Right-brained & 17 & .74 & .154 \\
\hline & Total & 61 & .76 & .173 \\
\hline
\end{tabular}

\section{Performance in inferential questions}

Inferential questions require the reader to draw inferences from the content. Research indicated that it is a right-hemispheric function. However, as is the case with main idea questions, left-brained participants reached the highest mean score in responses to such questions, as is clear in Table 4. The lowest mean score was obtained by RBLs. This result, with previous ones, lends support to the results of Croaker (1995) and Douglas (1982), among others that indicate the general low performance of right-brained participants in different reading tasks. The performance of left-brained participants was significantly higher than RBLs and WRBM in specifically answering these questions.

Table 4. Mean scores of answers to inferential questions

\begin{tabular}{l|l|l|l|l}
\hline & & & & \\
& & $\mathrm{N}$ & Mean & Std. Deviation \\
\hline Inferential & $\begin{array}{l}\text { Left-brained } \\
\text { Whole-brained } \\
\text { favoring left mode } \\
\text { Whole-brained }\end{array}$ & 10 & .59 & .156 \\
& $\begin{array}{l}\text { Whole-brained } \\
\text { favoring right mode } \\
\text { Right-brained }\end{array}$ & 13 & .43 & .192 \\
& Total & 61 & .36 & .152 \\
& & .35 & .058 \\
\hline
\end{tabular}

\section{Performance in text-bound questions}

Text-bound questions are mainly about the details which are stated in the passage. Questions are not about the major ideas in the passage, but rather mainly about the supporting details. The highest percentage of questions in the test are of this type. Focusing on details is a lefthemisphere function as previous research indicated. Left-brained participants, as well as wholebrained, performed the highest in answers to this type of questions. The lowest group was the 
whole-brained favoring right mode. It is evident that this group, along with right-brained, score the lowest in other types of questions as well.

Table 5. Mean scores of answers to text-bound questions

\begin{tabular}{l|l|l|l|l}
\hline & & & & \\
\hline Text-bound & Left-brained & N & Mean & Std. Deviation \\
\hline & $\begin{array}{l}\text { Whole-brained } \\
\text { favoring left mode }\end{array}$ & 16 & .55 & .210 \\
& Whole-brained & 5 & .47 & .174 \\
& Whole-brained & 13 & .55 & .087 \\
& favoring right mode & 13 & .44 & .134 \\
& Right-brained & 17 & .47 & .129 \\
& Total & 61 & .49 & .161 \\
\hline
\end{tabular}

\section{Performance in literal meaning questions}

Literal meaning questions require the reader to guess the meaning of a particular word from its context. The reader has to choose the best or closest synonym of the word. Deciding on the meaning of particular words may involve skills of both hemispheres, depending on the word itself, and the amount of integrated information required. Similar to the results of previous questions, left-brained performance is the highest, while the lowest is the performance of wholebrained favoring left-mode.

Table 6. Mean scores of answers to literal meaning questions

\begin{tabular}{c|c|c|c|c}
\hline & & & & $\begin{array}{c}\text { Std. } \\
\text { Literal meaning }\end{array}$ \\
& $\begin{array}{c}\text { Left-brained } \\
\text { Whole-brained }\end{array}$ & 16 & .50 & .115 \\
& $\begin{array}{c}\mathrm{N} \\
\text { favoring left mode } \\
\text { Whole-brained }\end{array}$ & 5 & .34 & .168 \\
& $\begin{array}{c}\text { Whole-brained } \\
\text { favoring right mode } \\
\text { Right-brained } \\
\text { Total }\end{array}$ & 13 & .30 & .130 \\
& 17 & .37 & .143 \\
& 61 & .39 & .161 \\
\hline
\end{tabular}

\section{Discussion and interpretation of the results of the first part of the study}

Overall results indicate that there are actual differences in the EFL reading comprehension performance among different hemisphericity groups. The results point up the superiority of LBLs over other hemisphericity groups in EFL reading comprehension performance, thus supporting the results of many studies in the literature which generally revealed that linguistic tasks are basically a left-brain function (e.g. Fromkin et al., 2007; Douglas, 1981; Riley, 1981). Left-brained participants scored the highest in total test score, and also in answers to all the four types of questions. Such findings contradict the suggestions of Robertson (2000), Qi et al. (2014), Qi et al. (2019) and Qi and Legault (2020) that more right hemisphere participation is noticed in the early stages of learning a second language. Differences between the English 
phonological alphabet system and Mandarin Chinese orthography may be responsible for the differences in results between various studies.

The results also show that the lowest EFL reading comprehension performance is scored by WRBM and RBLs. Such a finding is in keeping with many previous ones that indicate the lower level of right-brained individuals performing linguistic tasks (e.g. Croaker, 1995; Carthy, 1993; Douglas, 1981). However, in order to test whether the differences in the performance of hemisphericity groups are statistically significant, one-way ANOVA and Tukey HSD formulae were applied to the results.

The difference between the performance of left-brained participants on the one hand, and both right-brained participants as well as whole-brained participants favoring right mode, has proved to be statistically significant at the 0.05 alpha level, in favor of left-brained. In addition, there were statistically significant differences between these groups in their responses to inferential questions and literal meaning questions. The performance of left-brained participants was significantly higher than RBLs and WRBM in specifically answering these questions. This fact indicates that left-brained participants are more successful in the skills of drawing inferences, and guessing word meanings in context. Nevertheless, some studies (Prat, 2004; Virtue, 2003) revealed that such skills are originally right-brain processes. A possible explanation of this counter-finding is that in a second/foreign language, more left-brain participation is noticed, even in skills that were originally right hemispheric functions. It seems that in initial stages of learning a foreign language, the level of proficiency which is basically related to the left hemisphere predetermines the performance of participants even in right hemispheric skills, such as drawing inferences. The higher level of foreign language proficiency is clearly reflected in responses to literal meaning questions. Left-brained participants' vocabulary could be larger than right-brained, thus allowing them to perform significantly higher in literal meaning questions.

However, differences in the performance of main idea questions between left- and rightbrained participants were not statistically significant. The levels of the performance of participants are close. That is because right-brained participants are skilled in eliciting the main idea of a passage. Accordingly, they did not score as low as in other types of questions. It seems that the right hemisphere is responsible for determining main ideas of a reading passage even in the second/foreign language. This result also substantiates the fact that both hemispheres contribute to the processing of language, yet performing different functions.

Although answering text-bound questions seems to activate left hemispheric functions, yet the difference between the performance of hemisphericity groups was not statistically significant. It seems that the low EFL proficiency level of the sample has restricted the performance of even left-brained participants, and did not allow the differences between hemisphericity groups to emerge with sufficient clarity.

It is worth mentioning that the performance of WRBM is evidently closer to that of RBLs than to the performance of WBLs. They can be generally included under the category of RBLs, keeping in mind that this classification is based on the learners' description of themselves, which is more approximate than absolute. 
In addition, although the orthographies of Arabic and English are different, this fact did not activate more right-brain processes, although some studies expected the opposite (Douglas, 1982; Roberson; 1983). A possible reason is that the participants are well acquainted with English orthography. They do not spend time in visually figuring out the letters.

\section{Results of the second part of the study}

The second part of the study is intended to add evidence for the results of the first part of the study. It investigates the effect of using a visual tool to represent verbal input on the EFL reading comprehension of different hemisphericity groups. It answers the second question of the study which is:

2. Does the use of a visual tool (a right-brain function) significantly improve the levels of EFL readings of learners with different hemisphericity modes?

As illustrated in Table seven, the mean score of the experimental group in the pretest was 0.46, while it reached 0.55 in the posttest. Apparently, there is an increase in the participants' performance in the posttest. However, to ensure the significance of that increase, the paired $t$ test value was computed. According to the $t$ - distribution table, a value of -4.768 with $60 \mathrm{~d}$. $\mathrm{f}$. is significant (.000) at the 0.05 level. The answer to question two is yes. Overall, the performance of all learners significantly increased after using the visual tool.

Table $7 \quad t$-test comparison of the total mean scores of the experimental group in the pretest and posttest

\begin{tabular}{lllllll}
\hline Experimental group & Mean & $\mathrm{N}$ & Std. Deviation & $T$ & Df & $\begin{array}{c}\text { Sig. } \\
\text { tailed) }\end{array}$ \\
\hline Pretest & .46 & 61 & .120 & -4.768 & 60 & .000 \\
Posttest & .55 & 61 & .144 & & & \\
& & & & & & \\
\hline
\end{tabular}

To insure that this increase in the performance of the experimental group is because of the use of the visual tool, a comparison with the results of the control group is required. Although the EFL reading comprehension performances of the two groups in the pretest showed no significant differences (Table eight). The $t$-value 1.945 with d. f. 120 indicates that there is no significant difference (.054) between the performances of the two groups as measured at the 0.05 alpha level. However, the experimental group significantly outperformed the control group in the posttest. The $t$ value is 6.536 is significant (.000) at the 0.05 level. Such significant difference between the performances of the two groups is evidently the result of implementing the visual tool by the experimental group.

Table 8 t- test comparison of mean scores of the experimental group and the control group in the pretest

\begin{tabular}{|c|c|c|c|c|c|}
\hline Group & $\mathrm{N}$ & Mean & $\begin{array}{l}\text { Std. } \\
\text { Deviation }\end{array}$ & $\mathrm{df}$ & Sig. \\
\hline
\end{tabular}

Experimental

$\begin{array}{lllllll}\text { pretest } & 61 & .46 & .120 & 1.945 & 120 & .054\end{array}$


Arab World English Journal (AWEJ) Volume 12. Number 2. June 2021

Brain Hemisphericity and Saudi Students' EFL Reading

Almanea

\begin{tabular}{|c|c|c|c|c|c|c|c|}
\hline \multirow{5}{*}{$t-t e s t$} & Control pretest & 61 & .42 & \multicolumn{4}{|l|}{.114} \\
\hline & comparison of $t$ & near & of the & erimental g & up and & con & oup in the \\
\hline & Group & $\mathrm{N}$ & Mean & $\begin{array}{l}\text { Std. } \\
\text { Deviation }\end{array}$ & $\mathrm{t}$ & Df & $\begin{array}{l}\text { Sig. (2- } \\
\text { tailed) }\end{array}$ \\
\hline & $\begin{array}{l}\text { Experimental } \\
\text { posttest }\end{array}$ & 61 & .55 & .144 & 6.536 & 120 & .000 \\
\hline & Control posttest & 61 & .38 & .145 & & & \\
\hline
\end{tabular}

Results of the second part of the study in different types of questions

Table $9 t$ - test comparison of the experimental group's mean scores in answers to the four types of questions in the pretest and posttest

\begin{tabular}{lllllll}
\hline Experimental group & Mean & $\mathrm{N}$ & $\begin{array}{l}\text { Std. } \\
\text { Deviation }\end{array}$ & $\mathrm{T}$ & $\mathrm{Df}$ & $\begin{array}{l}\text { Sig. } \\
\text { tailed })\end{array}$ \\
\hline Main idea pretest & .76 & 61 & .179 & 5.103 & 60 & .000 \\
Main idea posttest & .55 & 61 & .249 & & & \\
\hline Inferential pretest & .41 & 61 & .158 & -6.079 & 60 & .000 \\
Inferential posttest & .58 & 61 & .167 & & & \\
\hline Literal meaning pretest & .36 & 61 & .152 & -4.684 & 60 & .000 \\
Literal meaning posttest & .49 & 61 & .161 & & & \\
\hline Text-bound pretest & .48 & 61 & .160 & -4.348 & 60 & .000 \\
Text-bound posttest & .58 & 61 & .187 & & & \\
\hline
\end{tabular}

Table nine shows results that indicate significant differences between the experimental group's EFL reading comprehension performance in the pretest and their performance in the posttest in all the four types of questions. First, the mean score of the answers to the main idea questions in the pretest is 0.76 , but it is not as high in the posttest 0.55 . After computing the ttest value to examine the significance of the difference 5.103 with 60 d.f., it is shown that the difference is significant (.000) at the 0.05 level, but in favor of the pretest. There is a significant decrease in the experimental group's answers to main idea questions after the use of the visual tool.

However, this is not the case in the performance in other types of EFL reading comprehension questions. The mean score of answers to the inferential questions in the pretest is 0.41 , while it reached 0.58 in the posttest. When comparing this increase in the posttest to the increase in answers to other types of questions, it becomes clear that the highest increase after the application of Mind Mapping ${ }^{\circledR}$ was in the inferential type of questions. To check the 
significance of the increase, the same $t$-test value was computed and measured in the $t$ distribution table, which indicated that the value of -6.079 with 60 d.f. is significant (.000) at the 0.05 alpha level.

Similar methods of analysis were used to examine the significance of the increase in answers to literal meaning questions and to text-bound questions. The mean score of answers to literal meaning questions rose from 0.36 in the pretest to 0.49 . The t-test value applied to the pretest and the posttest is -4.684 , which revealed a significant difference (.000) at the 0.05 alpha level between the performance in literal meaning questions in the pretest and that in the posttest, in favor of the posttest. Likewise, the mean score of answers to text-bound questions rose from 0.48 in the pretest, to 0.58 in the posttest. The $\mathrm{t}$ - value -4.348 indicated a significant increase (.000) at the 0.05 alpha level.

It can be generally concluded that the overall EFL reading comprehension performance of the participants in the experimental group significantly increased after the use of the visual tool Mind Mapping to summarize information in the texts. When analyzing the increase against performance in different reading comprehension question types, it has been demonstrated that there were significant increases in responses to inferential, literal meaning, and text-bound questions. The highest increase was in the performance in the inferential type of questions. However, answers to main idea questions displayed a significant decrease rather than an increase in the posttest. The following section analyzes the effect of the visual tool on different hemisphericity groups.

\section{Right-brained learners}

In order to test the effect of the visual tool on RBLs' reading comprehension, the matched ttest statistical procedure was applied to the data. Results show that there are significant differences between the performance of RBLs in the pretest and their performance in the posttest. The total mean score of learners increased from 0.44 in the pretest to 0.58 in the posttest. The t value -4.762 proved that this increase is significant (.000) on the 0.05 alpha level. Accordingly, the use of Mind Mapping ${ }^{\circledR}$ significantly increased the RBLs' total performance in EFL reading comprehension.

However, when comparing the means of specifically RBLs in main idea questions, it was found that the mean score in the pretest (0.74) was higher than in the posttest (0.56). The $t$ value 2.433 shows that this difference is significant (.027). Concerning performance of RBLs in the other three types of questions, analysis proved the existence of significant differences between the pretest and the posttest in favor of the posttest. The highest increase of right-brained performance is in inferential type questions with their mean score rising from 0.35 in the pretest to 0.61 in the posttest, followed by answers to text-bound questions which increased from 0.47 to 0.61. The lowest increase, nonetheless, is in the mean score of answers to literal meaning questions, which rose from 0.37 to 0.51 .

\section{Left-brained learners}

Although the mean scores of LBLs increased slightly in the posttest, mainly in the overall scores (from 0.51 to 0.52 ), inferential questions (from 0.52 to 0.55 ), literal meaning questions (from 0.42 to 0.43 ), and text-bound questions (from 0.50 to 0.57 ), that increase is statistically 
insignificant as shown by t-test values. Such a result reveals that the effect of the use of a visual tool on the EFL reading comprehension performance of LBLs was minor. This result is in contrast with the results of the RBLs, which exhibited a significant increase in the posttest. Regarding mean scores of answers to main idea questions, the result is in keeping with its counterpart in RBLs. There was a significant difference (.006) in the mean scores of the LBLs in main idea questions in the pretest and the posttest. That difference is in favor of the pretest.

3. Whole-brained learners favoring right mode

The comparison between means of total scores in the pretest and posttest of WRBM indicated that they increased from 0.41 to 0.54 in the posttest. By applying the t-test statistical procedure, that increase proved to be significant (.000) at the .05 alpha level. Such a result is in keeping with the result of RBLs who showed a significant improvement in the posttest, and is contrary to the result of LBLs, exhibiting an insignificant increase. These significant differences in favor of the posttest in the performance of WRBM are equally found in answers to inferential, literal meaning, and text-bound questions. The largest improvement is noticed in the performance on inferential questions rising from .36 to .59 , followed by literal meaning questions, rising from .30 to .51 . Text-bound questions similarly increased from .44 to .54 . When comparing the mean scores of answers to main idea questions, the result of this group of learners is consistent with the results of RBLs and LBLs which all exhibit a significant decrease in the mean scores of main idea questions in the posttest.

4. Whole-brained learners favoring left mode

By comparing the total mean scores of the pretest .45 and the posttest .59 , it is evident that the mean score of WBLM clearly increased in the posttest. However as in the results of the LBLs, that increase is statistically insignificant .076. Therefore, as it is the case in LBLs' performance after using the visual tool, the effect of using mind maps by WBLM on the EFL is slight.

In answers to inferential and text-bound questions, there was a similarly insignificant increase. The scores in literal meaning questions likewise increased from 0.34 in the pretest to 0.53 in the posttest. That increase in this type of questions is significant 0.040 at the 0.05 alpha level. In all the mean scores, although the increase is insignificant, it was nonetheless greater than the increase in the mean scores of LBLs. In addition, like results of previous groups in regard to main idea questions, performance of WBLM decreased in the posttest. Nevertheless, the difference between mean scores of this group of learners in the pretest and in the posttest is insignificant.

\section{Whole-brained learners}

The comparison between the total mean scores of the whole-brained learners in the pretest 0.50 and in the posttest 0.49 indicate that the performance is almost at the same level in the two tests. There was no significant increase in the posttest. Although there was an increase in the mean scores of answers to inferential questions and to literal meaning questions, that increase was insignificant at the 0.05 alpha level. Concerning text-bound questions and main idea questions, the performance of WBLs was higher in the pretest than in the posttest, although the difference was insignificant. 


\section{Discussion of the results of the second part of the study}

By comparing the results of the five hemisphericity groups, it can be concluded that the effect of using a visual tool (Mind Mapping $®)$ to aid foreign language reading comprehension is different among various hemisphericity groups. RBLs and WBRM showed a significant increase in the posttest after implementing the visual tool. In both cases, the greatest development is specifically in answers to the inferential type of questions. Inferential questions require the pragmatic skill of drawing an inference, which is a right- hemisphere function. Although there has been an increase in the performance of LBLs and whole-brained learners favoring left mode, that increase was statistically insignificant. The performance of WBLs continued to be of similar levels in the pretest and the posttests.

Overall, the analysis of data showed that using a visual tool and composing a mind map after reading a passage raised the level of comprehension of the material. Such a result is expected, since Mind Mapping ${ }^{\circledR}$ is a brain-based strategy that visually assists the verbally-stated text. Accordingly, this study has confirmed the views of Mento et al. (1999) and Walker (1995), which indicated that allowing hemispheric interplay by using tasks that activate both hemispheres resulted in a significantly better brain response.

This finding shows that visual tools such as Mind Mapping® best suit RBLs and WBRM. It was expected that RBLs would benefit more from Mind Mapping, because it activates many abilities of the right-hemisphere, since it is a visual, spatial, colorful, and holistic strategy. Such a result is in keeping with that of Seng and Yeo (2000) who found RBLs to be the best performers in a spatial ability test. LBLs and WBLM slightly benefited from the strategy, since it activates both hemispheres, but their increase was not as great as that of RBLs and WBRM. The performance of WBLs continued to be at the same level in both the pretest and the posttest, because they are equally adept at using their two hemispheres efficiently.

The analysis of the visual tool's effect on different reading comprehension skills showed that it developed three of the reading comprehension skills tested in the study, namely drawing inferences about the content, understanding word meanings in context, and answering specific text-based questions.

Mind Mapping @ supported the skill of understanding word meanings in context, possibly because learners were able to build their selection of the best synonym on the basis of information summarized and integrated in the mind map. This finding is in agreement with Ou (2006), who found that composing a summary supported the understanding of word meanings in context, since the summary assisted the selection of the most appropriate synonym.

Similarly, the visual tool assisted the skill of answering specific text-based questions since the learner restated the hierarchies of details in the mind map. Relationships between ideas of the text become clearer and visual in the mind map. In addition, details of the text are supported with visual aids which make remembering them and answering questions about them easier. Restating these details of the text supports understanding them, since the reader not only receives them as informational input, but also reproduces them in the mind map. Pan's (2005) and Watson's (2005) comments are in agreement with this finding, as they argued that graphic organizers facilitate locating key ideas in a text and recognizing the text's structure and organization. 
However, the largest significant positive effect of the visual tool, as expressed in the analysis of the data, is measured in answers to inferential questions. The tool developed experimental group participants' skill in drawing inferences in the posttest, most probably because it gives a holistic view of the text. The visual, complete, and unified view of the topic easily guided the reader to determine why the writer included some piece of information, and to find or "see" the verbally unstated relationship between the topic as a whole and that specific information. This is not the case in linear reading, where the readers often lose track, and may forget information read before as they proceed. Furthermore, the mind map clarifies the writer's intent to include certain ideas, since in the mind map relationships between the topics' components and their organizations are visually displayed with requisite clarity. In the main, the reader primarily needs this information about the topic, in order to generate and build his/her inference from it. This explanation of the possible reason behind the highest increase in answers to inferential questions is supported by Mason and Just's (2004) finding that drawing an inference requires a sufficient amount of integration of information presented in the text. It is thus no surprise that the use of Mind Mapping®, which synthesizes the information presented in the text, enhanced learners' scores in answers to inferential questions.

The improvement in the participants' skill of drawing an inference after composing a mind map concurs with the conclusions of Prat (2004) and Virtue (2003). Both Prat (2004) and Virtue (2003) found that the right hemisphere participates to a notable degree in drawing an inference. According to Virtue (2003), the right hemisphere activates information and generates possible meanings of the inference, while the left hemisphere is responsible for selecting the appropriate meaning of the inference. Based on their results, the visual tool Mind Mapping®, which activates the right hemispheric abilities, raised the learners' level in answers to inferential questions.

Participants' answers to main idea questions, contrary to expectations, digressed in the EFL reading comprehension posttest. Nevertheless, after checking all of their mind maps, it was found that most of them understood the main idea of the passage, since they drew a central image correctly representing that main idea. Their abilities in representing the main idea in their mind maps are significantly better then their level in answering main idea questions.

It can be noticed that the mean scores of the experimental group in answers to main idea questions in the pretest were the highest among answers to other types of questions. They were far higher than answers to other types of questions. This indicates that the participants' answers to main idea questions were exceptional. The most plausible explanations for this result is that when taking the first test, learners were very enthusiastic and extremely precise, using their full understanding potential to work out answers to the questions. Yet for the posttest, their motivation clearly decreased because they had completed a similar test before. It could be argued that this effect of lack of motivation is clear only in answers to main idea questions because answering these questions requires careful and attentive reading to grasp the topic as a whole. This is not the case in other types of questions, which ask about some specific information in the text without the need for relating ideas to each other.

\section{Conclusion}

This study investigated the relationship between the phenomenon of hemisphericity and EFL reading comprehension. A general conclusion of the study is that there is an actual role played by 
brain hemisphericity affecting the level of EFL reading comprehension. The first part of the study revealed that the performance of LBLs was significantly higher than the performance of RBLs. LBLs scored the highest in answers to different reading comprehension questions; namely main idea questions, inferential questions, literal meaning questions and text-bound questions. The results indicated that with low-proficiency and at early stages of reading in a foreign language, more participation is expected from the left hemisphere of the brain. The study also revealed that the performance of RBLs and WBRM is the lowest among the groups. This result suggests that even in a foreign language learned after childhood, the left hemisphere seems to control brain activities dealing with language.

Results of the second part of the study showed that overall performance of all learners improved with the use of the visual aid. Using a visual tool that suits right hemispheric functions and allows a balance between left and right hemisphere functions generally assisted EFL reading comprehension. The EFL reading comprehension performance of the experimental group significantly increased after the use of Mind Mapping ${ }^{\circledR}$. There was no parallel increase in the performance of the control group. This result adds evidence to the efficacy of the visual tool in supporting EFL reading comprehension.

After comparing the performance of different hemisphericity groups, RBLs and WBRM proved to perform significantly higher in the posttest because they benefited from the visual tool. This result was expected since the brain-based tool Mind Mapping (®) is a holistic, visual, colorful and spatial tool that activates many right hemispheric functions. Significant improvements in the EFL reading comprehension performance of those learners were evidenced in their answers to inferential, literal meaning, and text-bound questions. Their greatest increase was in their mean scores in answers to inferential questions which require drawing inferences about the text. Drawing inferences and understanding the author's intent is a pragmatic skill related to the right hemisphere.

Although there has been an increase in the performance of LBLs and whole-brained learners favoring left mode with the use of the visual tool, that increase was statistically insignificant. The performance of WBLs continued to be of similar levels in the pretest and the posttests.

As the study showed, learners with different modes of hemisphericity clearly learn in different ways. The study indicated that methods and practices of learning and teaching a foreign language which tend to concentrate on left-brain processes actually serve to deprive RBLs specifically of the chance to utilize their right-brain skills. A pedagogical implication of the results is to give all learners an opportunity to activate both hemispheres. Balanced brain-based methods and strategies, such as the different visual tools, need to be incorporated in the system of learning and teaching.

There is a need to use a variety of methods and tools, such as brain imaging or MRI, to evaluate the relationship between hemisphericity and EFL reading comprehension and to validate the present study's findings. It is also recommended for future research to investigate the relationship between brain hemisphericity and EFL among learners of different proficiency levels and with different L1s. Research in these areas may reveal many insightful findings, with beneficial and practical research implications. 


\begin{abstract}
About the author:
Dr. Manar Almanea is an assistant professor of applied linguistics at the College of Languages and Translation in Imam Mohammad Ibn Saud Islamic University. Her research interests lie primarily in the areas of psycholinguistics and second language acquisition with a specific focus on Arabic. ORCID: https://orcid.org/0000-0002-3615-2394
\end{abstract}

\title{
References
}

Bogen, J. E. (1975). Some educational aspects of hemispheric specialization. UCLA Educator, 17,2, 2432.

Buzan, T. , \& Buzan, B. (2003). The mind map book. London: BBC Worldwide.

Carthey, J. H. (1993). Relationships between learning styles and academic achievement and brain hemispheric dominance and academic performance in business and accounting courses. (Unpublished MA Thesis). University of Pittsburgh. Available from ERIC. (62713063; ED374412). Retrieved from https://www-proquest-com.sdl.idm.oclc.org/dissertationstheses/relationships-between-learning-styles-academic/docview/62713063/se2 ? accountid $=142908$.

Chuang, L. (2006). Whole-brain paths to language learning: An English instructional model. Journal of Humanities and Social Sciences. 2 (1), 1-5.

Croker, R. E. Bobell, J., \& Wilson, R. A. (1995). Learning style, brain modality, and teaching preferences of incarcerated females at the Pocatello Women's Correctional Center. Paper presented at the American Vocational Association Convention. Denver, CD, December, 4.

Douglas, E. (1982). Some relationships between neuropsychological measures of hemispheric skills and second language learning proficiency. (Unpublished MA Thesis), University of Pittsburgh.

Fromkin, V. Rodman, R. \&Hyams, N. (2007). An introduction to language. Boston: Thomson Wardsworth.

Lieberman, M. G. (1986). The hemispheric mode indicator technical notes. Barrington, IL: Excel, Inc.

Mason, R. A., \& Just, M. A. (2004). How the brain processes casual inferences in text. American Psychological Society, 15 (1), 1-7.

McCarthy, B. (1987). The 4MAT system. Barrington, IL: Excel, Inc.

McCarthy, B., \& Germain, C.S. (1993). Hemispheric mode indicator (hmi). Barrington, IL: Excel, Inc.

Mento, A. J., Martinelli, P., \& Jones, R. M. (1999). Mind mapping in executive education: applications and outcomes. The Journal of Management Development, 18 (4) 390-416 DOI: $10.1108 / 02621719910265577$

Morton, B., \& Rafto, E. (2006).Corpus callosum size is linked to dichotic deafness and hemsihpericity, not sex or handedness. Brain and Cognition, 62, 1 -8.

Morton, B., \& Rafto, E. (2010). Behavioral Laterality Advance: Neuroanatomical Evidence for the Existence of Hemisity. Personality and Individual Difference, 49,1, 34-42 DOI: https://doi.org/10.1016/j.paid.2010.03.001

$\mathrm{Ou}, \mathrm{F}$. (2006). The effect of the summarization strategy on reading comprehension of non-proficient Taiwanese university EFL learners. Unpublished $\mathrm{PhD}$ dissertation. University of Kansas. Available from ProQuest Dissertations \& Theses Global. (305322248). Retrieved from https://www-proquestcom.sdl.idm.oclc.org/dissertations-theses/effects-summarization-strategy-onreading/docview $/ 305322248 /$ se-2?accountid $=142908$

Pan, L. M. (2005). The implication of schema theory, metacognition and graphic organizers in English reading comprehension for technical college students in Taiwan. Unpublished $\mathrm{PhD}$ dissertation. Spalding University. Available from ProQuest Dissertations \& Theses Global. (304918164). Retrieved from https://www-proquest-com.sdl.idm.oclc.org/dissertations-theses/implicationschema-theory-metacognition-graphic/docview/304918164/se-2?accountid=142908 
Prat, C. S. (2004). Hemispheric differences in discourse representations: Insight into right hemisphere discourse processes. Unpublished $\mathrm{PhD}$ dissertation. University of California Davis. Available from ProQuest Dissertations \& Theses Global. (304918164). Retrieved from https://www-proquestcom.sdl.idm.oclc.org/dissertations-theses/implication-schema-theory-metacognitiongraphic/docview/304918164/se-2?accountid=142908

Qi, Z., Han, M., Wang, Y., Angeles, C., Qi, L., Garel, K., Chen, E., Whitfield-Gabrieli, S. Gabrieli, J, \&Perrachione, T. (2014). White-matter structure in the right hemisphere predicts Mandarin Chinese learning success, Journal of Neurolinguistics. http://dx.doi.org/10.1016/j.jneuroling.2014.08.004

Qi, Z,. Han, M., Wang, Y., Los Angeles, C.D., Liu, Q., Garel, K.,Chen, E. S., Whitfield-Gabrieli, S., Gabrieli, J., Perrachione, T. (2019). Speech processing and plasticity in the right hemisphere predict variation in adult foreign language learning. NeuroImage ,192, 76-87.

Qi, Z., \& Legault, J. (2020). Neural hemispheric organization in successful adult language learning: Is left always right? Psychology of Learning and Motivation, 72, 119-163. https://doi.org/10.1016/bs.plm.2020.02.004

Riley, P. J. (1981). A comparison of brain dominance and placement examination scores on entering students: Cerro Coso Community College. Unpublished PhD dissertation. Brigham Young University.

Robertson, J. (2000). Increasing access to modern foreign languages to pupils with special educational needs: A neuropsychological perspective. Modern Foreign Languages. 15, (2), 62-66.

Saleh, A. (2001). Brain hemisphericity and academic majors: A correlation study. College Student Journal. 35 (2), 193-200

Seliger, H. W. (1982). On the possible role of the right hemisphere in second language acquisition. TESOL Quarterly, 16 (3), 307-314

Seng, S. \& Yeo, A. (2000). Spatial visualization ability and learning style preference of low achieving students. Paper presented to U. S. Department of Education, National Institute of Education. Nanyang Technological University: Singapore.

Tan, E. Y. L. (1982). Mixed dominance and its relationship to the learning process with preference to reading. Unpublished $\mathrm{PhD}$ dissertation. Seattle, WA: Seattle University. Available from ProQuest Dissertations \& Theses Global. (303256319). Retrieved from https://www-proquestcom.sdl.idm.oclc.org/dissertations-theses/mixed-dominance-relationship-learningprocess $/$ docview $/ 303256319 / \mathrm{se}-2$ ?accountid=142908

Virtue, S. M. (2003). Hemispheric processing of anaphoric inferences during reading: Selection of multiple antecedents. Unpublished $\mathrm{PhD}$ dissertation. University of Minnesota. Available from ProQuest Dissertations \& Theses Global. (305308788). Retrieved from https://www-proquestcom.sdl.idm.oclc.org/dissertations-theses/hemispheric-processing-anaphoricinferences/docview/305308788/se-2?accountid=142908

Walker, D. M. (1995). Connecting right and left brain: Increasing academic performance of African American students through the use of arts. Paper presented at the Annual Meeting of National Alliance of Black School Educators 25th, Dallas, TX, November .

Watson, C. A. (2005). Graphic organizers: Toward organization and complexity of students content knowledge. Unpublished PhD dissertation. Virginia Polytechnic Institute and State University. Available from ProQuest Dissertations \& Theses Global. (305416052). Retrieved from https://www-proquest-com.sdl.idm.oclc.org/dissertations-theses/graphic-organizers-towardorganization-complexity/docview/305416052/se-2 ?accountid=142908

Williams, M. H. (1999). The effects of a brain based learning, mind mapping, on the achievement of adults in a training environment with consideration to learning styles and brain hemisphericity. Unpublished $\mathrm{PhD}$ dissertation. University of Texas. Available from ProQuest Dissertations \& Theses Global. (304460959). Retrieved from https://www-proquestcom.sdl.idm.oclc.org/dissertations-theses/effects-brain-based-learning-strategy$\mathrm{mind} /$ docview/304460959/se-2?accountid=142908 